\title{
Analytical Network Process in the Framework of SWOT Analysis for Strategic Decision Making (Case Study: Technical Faculty in Bor, University of Belgrade, Serbia)
}

\author{
Živan Živković, Djordje Nikolić, Predrag Djordjević, \\ Ivan Mihajlović, Marija Savić \\ University of Belgrade, Technical Faculty in Bor \\ Vojske Jugoslavije 12, 19210 Bor, Serbia \\ zzivkovic@tf.bor.ac.rs, djnikolic@tt.bor.ac.rs, pdjordjevic@tt.bor.ac.rs, \\ imihajlovic@tf.bor.ac.rs,msavic@tf.bor.ac.rs
}

\begin{abstract}
In this study Analytical Network Process (ANP) was applied as a model for prioritizing generated strategies based on the factors and sub-factors within the SWOT analysis, in the case of the Technical Faculty in Bor (TFB), University of Belgrade (UB), Serbia. ANP methodology approach implies the establishment of a hierarchical model on four levels: Goal (selection of the best strategy) - SWOT factors - SWOT sub-factors alternative strategies, which establishes the interaction between clusters at different hierarchical levels of the model as well as the interactions between the elements within each cluster. This paper demonstrates a process for quantitative SWOT analysis that can be performed even when there is dependence among strategic factors. The proposed algorithm uses the ANP, which allows measurement of the dependencies among the strategic factors, as well as AHP, which is based on the independences between the factors. Dependencies among the SWOT factors and sub-factors are observed and their relative importance weights are determined, as well as their impact on the prioritization of the development strategy. The resulting benchmarking and prioritization of the alternative strategies in a series $W O_{1}-S O_{1}-S T_{1}-W T_{1}$ for the development period of the TFB until 2025, indicates the sequence of application of certain strategies. This sequence implies that after reaching the limits in the application of the first strategy the next strategy in the defined sequence is implemented, in accordance with the mission of the TFB, the adopted strategic goals (SC) and adopted vision for the next ten-year period.
\end{abstract}




\section{Introduction}

Strategic management includes a series of decisions and management actions in order to achieve the defined long-term goals of the company [1]. In this strategic management process a number of tools and techniques are used, among which analysis of Strengths, Weaknesses, Opportunities and Threats - (SWOT) has a special role [2]. SWOT analysis is a decision support tool and it is used as a tool for internal analysis as well as the analysis of the organizational environment. The obtained information can be systematically represented in a matrix, different combinations of the four factors from the matrix can aid in determining strategies for long-term progress [3-5]. However, this method does not provide analytical possibilities for quantification of the identified factors that are usually briefly and very generally described, and which represents a major disadvantage of SWOT analysis in strategic decision-making process $[3,6]$.

Through identifying strengths and weaknesses as a result of internal analysis,opportunities and threats as a result of the environment, organizations can build strategies that rely on strengths to reduce the perceived weaknesses, utilize identified opportunities and define a plan of actions to reduce or eliminate the impact of threats [7]. Acquired information can be systematically presented in the form of a SWOT matrix. In recent times different analytical methods have been developed which allow to determine the prioritization of long-term development strategies of the company, with different combinations of the four SWOT factors $[3,8,9]$.

In order to eliminate weaknesses in the measurement and evaluation of steps in the SWOT analysis, a hybrid AHP method was developed [3], to quantify the weight of SWOT factors, which was named A'WOT in later studies [10-11]. This model has been tested in numerous studies, and despite its limitations, it is still widely used today [12-14]. AHP approach assumes that the factors presented in the hierarchical structure are independent. This approach can be questioned if the dependency between the SWOT factors is established, which can be determined by internal analysis of the organization and with the environment analysis [8].

The organization can make a good use of the opportunities if it has resources and strength to express its superiority, otherwise the opportunities will be lost because competitors will use them [8]. A similar relationship exists between strengths and threats. The ability to provide an adequate response to threats is based on the strength of the organization to eliminate or reduce the impact of threats. The dependency between the strengths and weaknesses in an organization is such that organizations with major strengths probably have fewer weaknesses, and therefore can more easily deal with situations which arise from the defined weaknesses. Organizations with more weakness relative to their competitors are more vulnerable to threats. These facts indicate that SWOT factors are not mutually independent, while factor weights of mutual connections depend on the specifics 
of each organization [9]. Since the weight parameters are traditionally assign to factors as if there is no interdependence between them, under the conditions of existing interdependence the weight parameters can have different values, which directly affects the prioritization of the strategies $[9,15,16]$.

Initial study developed in the eighties of the $20^{\text {th }}$ Century [17] defined the AHP as a methodology of multicriteria decision making for complex problem solving. This method is a framework designed to cope with the intuitive, the rational, and the irrational when multi-objective, multi-criterion, and multi-actor decisions are made, with or without certainty for any number of alternatives. A basic premise of the AHP is the requirement of the functional independence of individual higher parts in the hierarchy from their lower parts, as well as between sub-factors within the same level. Many decision problems cannot be structured hierarchically because many factors from higher levels are related with lower levels as well as within the same level. Structuring problems with functional dependencies which allow feedback between the clusters represents Analytical Network Process (ANP). Saaty proposed the use of the AHP approach to solve problems in systems where there is independence between alternatives or criteria, and to use the ANP for systems in which there are direct or indirect connections between the individual levels [18]. For example, the importance of the criterion does not only affect the importance of the alternative, but also the importance of alternative affects the importance of the criterion. In addition, the elements of the cluster may affect some or all of the elements of any other cluster. Inner dependencies among the elements of a cluster are represented by looped arcs [9].

Implementation of the ANP methodology generally consists of four steps which are described in detail in the literature $[8,16]$. ANP methodology is used in many complex systems in which interactions, in a hierarchical structure, occur between the level of clusters as well as between the elements within the cluster, which in the case of SWOT analysis clusters of factors and sub-factors could be used for prioritization of the strategies $[8,9,15,16]$.

In this study, ANP is used to define the relationship between the SWOT factors, SWOT factors and SWOT sub-factors, as well as between the sub-factors, for the purpose of the prioritization of the strategies. At the same time, the AHP method is used to determine the factor weights of dependency or independency and their influence on the selection of alternative strategies. The application of this methodology will be tested on a case of defining and prioritization of the strategies for the development of the Technical Faculty in Bor (TFB), University of Belgrade, Serbia by 2025. This tool, and obtained results, can be a starting point for benchmarking the operation of the TFB and further increasing its competitive position in the region. 


\section{Application of ANP Method on the Results of SWOT Analysis}

The hierarchical and network model proposed for the SWOT analysis in this study consists of four levels, as shown in Figure 1. Goal (best strategy) represents the first level, the criteria (SWOT factors) represent the second level, sub-criteria (SWOT sub-factors) represents the third level and alternatives represents the fourth level (alternative strategies).

The hierarchical view of the SWOT model is shown in Figure 1a, while the general network model is presented in Figure $1 \mathrm{~b}$.

a)

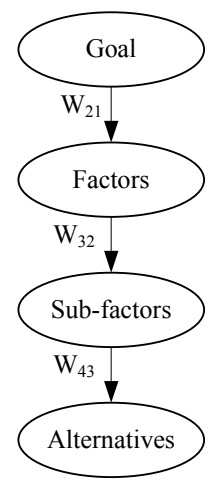

b)

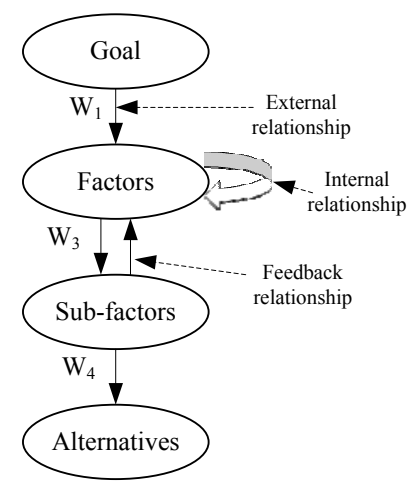

Figure 1

Comparison of the AHP and ANP structures - a) hierarchical model; b) network model

ANP model (Figure 1b) is an enhanced version of the AHP method, which more precisely defines the relationships in complex models that use many criteria, feedback and interdependence between the criteria. An advantage of this method is that it easily defines decision-making problem which includes many complicated relations. ANP method defines all components and relationships as bidirectional interactions. ANP includes relationships between individual clusters at different hierarchical levels, as well as the interactions between criteria and subcriteria, therefore, this method is useful for obtaining more accurate and efficient results in decision-making in complex systems. Figure $1 \mathrm{~b}$ illustrates that all criteria and clusters are interconnected through one of the potential links: unidirectional, bidirectional or loops. Unidirectional or bidirectional connection represents a connection between the clusters, while looping represents internal dependency in the cluster. The relative importance of the element $i$ in relation to the element $j$ is presented as:

$\mathrm{a}_{\mathrm{ij}}=\mathrm{w}_{\mathrm{i}} / \mathrm{w}_{\mathrm{j}}$

in the pairwise comparison matrix. 
The pairwise comparison matrix A with $n$ elements to be compared is formed as in eq. (3) [9]:

$$
\mathrm{A}=\left(\mathrm{a}_{\mathrm{ij}}\right)_{\mathrm{nxn}}=\left[\begin{array}{cccc}
\mathrm{a}_{11} & \mathrm{a}_{12} & \ldots & \mathrm{a}_{1 \mathrm{n}} \\
1 / \mathrm{a}_{12} & \mathrm{a}_{22} & \ldots & \mathrm{a}_{2 \mathrm{n}} \\
\ldots & \ldots & \ldots & \ldots \\
1 / \mathrm{a}_{1 \mathrm{n}} & 1 / \mathrm{a}_{2 \mathrm{n}} & \ldots & \mathrm{a}_{\mathrm{nn}}
\end{array}\right]=\left[\begin{array}{cccc}
\mathrm{w}_{1} / \mathrm{w}_{1} & \mathrm{w}_{1} / \mathrm{w}_{2} & \ldots & \mathrm{w}_{1} / \mathrm{w}_{\mathrm{n}} \\
\mathrm{w}_{2} / \mathrm{w}_{1} & \mathrm{w}_{2} / \mathrm{w}_{2} & \ldots & \mathrm{w}_{2} / \mathrm{w}_{\mathrm{n}} \\
\ldots & \ldots & \ldots & \ldots \\
\mathrm{w}_{\mathrm{n}} / \mathrm{w}_{1} & \mathrm{w}_{\mathrm{n}} / \mathrm{w}_{2} & \ldots & \mathrm{w}_{\mathrm{n}} / \mathrm{w}_{\mathrm{n}}
\end{array}\right]
$$

After completion of the matrix A, assessment of the relative importance of the elements is performed by calculation according to the equation (4):

$\mathrm{Aw}=\lambda_{\max } \cdot \mathrm{w}$

where:

$\lambda_{\max }-$ largest eigenvalue of the matrix $\mathrm{A}$,

$\mathrm{w}$ - desired estimate.

AHP and ANP are popular methods also because they have the ability to identify and analyze inconsistencies of decision makers in the process of discernment and evaluation of the elements of the hierarchy [17]. If the values of the weight coefficients of all the elements that are mutually compared at a given hierarchy level could be precisely determined, the eigenvalues of the matrix A would be entirely consistent, however, this is relatively difficult to achieve in practice. Therefore, the application of these methods provides the ability to measure errors of judgment by computing consistency index (CI) for the obtained comparison matrix A, and then to calculate the consistency ratio (CR) [18].

In order to calculate the consistency ratio (CR), the consistency index (CI) needs to be calculated first, according to the following relation:

$$
\mathrm{CI}=\frac{\lambda_{\max }-\mathrm{n}}{\mathrm{n}-1}
$$

Then, the consistency ratio is determined by equation:

$$
\mathrm{CR}=\frac{\mathrm{CI}}{\mathrm{RI}}
$$

where RI is a random index which depends on the order $\mathrm{n}$ of the matrix $\mathrm{A}$, and is taken from the Table 1 [18].

Table 1

Random indices (RI)

\begin{tabular}{cccccccccc}
\hline $\begin{array}{c}\text { n-order of the } \\
\text { matrix A }\end{array}$ & 1 & 2 & 3 & 4 & 5 & 6 & 7 & 8 & 9 \\
\hline RI & 0.00 & 0.00 & 0.58 & 0.90 & 1.12 & 1.24 & 1.32 & 1.41 & 1.45 \\
\hline
\end{tabular}


If the consistency ratio (CR) is less than 0.10 , the result is sufficiently accurate and there is no need for adjustments in the comparisons and recalculation of the weights. However, if the consistency ratio is greater than 0.10 , the results should be re-analyzed and the reasons for the inconsistencies should be identified and then removed by partial repetition of the pairwise comparison.

ANP approach consists of the following three matrices: supermatrix, weighted supermatrix and limit matrix. In the supermatrix the relative importance of all components is provided, in the weighted supermatrix the values obtained from the supermatrix of each cluster are defined. In the limit matrix, the constant values of each value are determined by taking the necessary limit of the weighted super matrix [9]. The results of the decision making problem is obtained from the limit matrix scores [18].

The basic steps in the proposed SWOT-ANP model consist of the following. In the first step, SWOT factors, SWOT sub-factors and alternatives are identified. The procedure of obtaining importance of the SWOT factors, which represents the first step of the matrix manipulation concept of the ANP concept, is fully described in the literature $[12,19,20,21]$. According to inner dependencies between the SWOT factors, inner dependency matrix is obtained and used to correct SWOT factor matrix. Then, SWOT sub-factors weights and priority vectors for alternative strategies are determined. Based on the schematic representation on Figure $1 \mathrm{~b}$ the general supermatrix for the SWOT model which was used in this paper has the following form:

$$
\mathrm{W}=\underset{\substack{\text { SWOT factors } \\
\text { SWOT sub-factors } \\
\text { Alternatives }}}{\text { Sleal }}\left[\begin{array}{cccc}
0 & 0 & 0 & 0 \\
\mathrm{~W}_{1} & \mathrm{~W}_{2} & 0 & 0 \\
0 & \mathrm{~W}_{3} & 0 & 0 \\
0 & 0 & \mathrm{~W} 4 & \mathrm{I}
\end{array}\right]
$$

where:

$\mathrm{w}_{1}$ - vector that represents the impact of the goal on the selection of the best strategy based on the SWOT factors

$\mathrm{W}_{2}$ - matrix that indicates the internal interdependence of the SWOT factors

$\mathrm{W}_{3}$ - matrix which indicates the influence of the SWOT factors on the SWOT subfactors,

$\mathrm{W}_{4}$ - matrix that identifies the impact of the SWOT sub-factors on the alternatives.

It is preferable to present the details of the obtained results in this algorithm by using matrix operations.

In order to apply the ANP in the matrix operations for the purpose of determining the priorities of identified alternative strategies based on the SWOT analysis, the following steps are recommended $[8,9,15]$ : 
Step 1) Identify SWOT sub-factors and determine the alternative strategies according to SWOT sub- factors.

Step 2) In this step the importance of each SWOT group (strengths, weaknesses, opportunities and threats) is determined by calculating the weight matrix w1, while considering the situation that there is no internal interdependence between the SWOT factors.

Step 3) Calculation of the $\mathrm{W}_{2}$ - inner dependence matrix of SWOT factors, using a scheme of internal interdependence shown in Figure 2

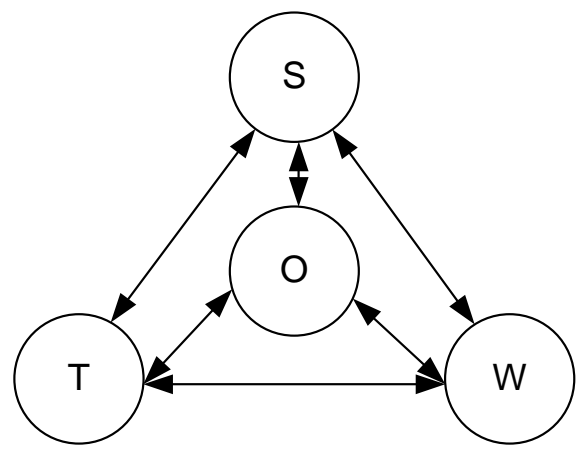

Figure 2

Internal interdependence of SWOT factors

Step 4) Calculating the weight matrix $\mathrm{w}_{\mathrm{SwOTfactors}}=\mathrm{W}_{2} \times \mathrm{w}_{1}$, of interdependent priorities of SWOT criteria - the factors.

Step 5) Determining the importance of SWOT sub-criteria within the third level of the model proposed in Figure $1 \mathrm{~b}$ and formation of the matrices $\mathrm{w}_{\text {SwOTsub-factors(local) }}$ with respect to each SWOT factor (Strengths, Weaknesses, Opportunities and Threats). Evaluation of comparative pairs of SWOT sub-criteria and determination of their local importance relative to a higher level in the model, is implemented based on Saaty's scale 1-9 [18].

Step 6) Determination of global importance of SWOT sub-criteria, i.e. the values of the weight matrix $\mathrm{W}_{3}=\mathrm{w}_{\mathrm{SWOTsub-factor(global)}}=\mathrm{w}_{\text {factors }} \times \mathrm{w}_{\mathrm{SWOTsub-factors(local)}}$ are determined.

Step 7) The importance of each considered strategic option is determined in relation to the defined subcriteria of SWOT factors, by rating the comparative pairs of options using Saaty's scale 1-9 [18]. In this way weight matrix of importance of alternative strategies is created relative to the SWOT sub-criteria, i.e. the matrix $\mathrm{W}_{4}$.

Step 8) Determination of the overall importance of strategic options in the model, by forming a weighted matrix $\mathrm{w}_{\text {alternatives }}=\mathrm{W}_{4} \times \mathrm{w}_{\text {SWOTsub-factors(global) }}$. 


\section{The Prioritization of Alternative Strategies Based on the SWOT Analysis}

In this paper, the ANP methodology is applied for the selection of priority of alternative strategies, based on the results of the SWOT analysis (defined SWOT factors and SWOT sub-factors), for the case of TFB for the period up to 2025.

The SWOT analysis for the TFB had been prepared for the purpose of the second round of national accreditation in 2013. The SWOT analysis was conducted through a few rounds of brainstorming, where between 70 and 80 professors and assistants had been participating [22], while the obtained results were adopted by the professional and management bodies of the TFB. The obtained results are shown in Table 2.

Step 1) Based on the results of the SWOT analysis which define the current state of the TFB, by comparing the SWOT factors: strengths, weaknesses, opportunities and threats, as well as sub-factors within each factor, the possible future development strategies of the TFB were defined until the year 2025 [7, 8, 9]. The analytic network structure of the MCDM model, which was used in this study, is shown in Figure 3.

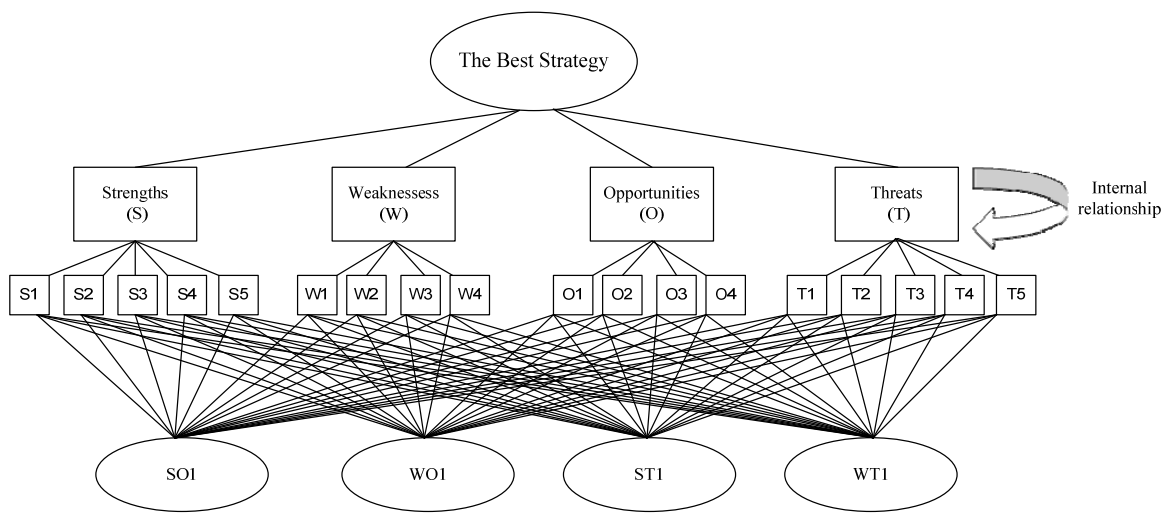

Figure 3

AHP model for the selection of the best strategy

The results shown in Table 2 identified the following strategies:

- $\mathrm{SO}_{1}$ : Strategy for development of new markets (Providing students from the new markets in the country and abroad, as well as opening of departments outside the seat of the Faculty. TFB has previous experience with this type of activities).

- $\mathrm{WO}_{1}$ : Strategy of the shift in the management of the Faculty (Moving from the current strategy: non-transparent management and retention of 
the status quo into a transparent and aggressive strategy of making changes in order to ensure growth and development).

- $\mathrm{ST}_{1}$ : The strategy of new product development (development of new and attractive study programs which would be of interest for potential students)

- $\mathrm{WT}_{1}$ : Strategy for the development of strategic partnerships within the $\mathrm{BU}$ and the EU (creation of joint programs and issuance of double degrees with other units of BU and universities from the EU).

By combining the SWOT, factors and sub-factors within each factor, possible alternative SO, WO, ST and WT strategies were defined, which derive from the adopted mission statement of the TFB: "The purpose of the TFB's existence is to provide an adequate response to the needs of young generation for the higher education. The best in our field will be chosen as benchmarking partners in the realization of the educational process. Also, alternative strategies are aligned with the vision document of the TFB: "Vision of the TFB is that it becomes recognized in the educational space of South East Europe through achieving above-average results in science and education" [22].

Table 2

SWOT analysis for the TFB

\begin{tabular}{|c|c|c|}
\hline & Internal factors & \\
\hline \multirow{6}{*}{ External factors } & Strengths (S) & Weaknesses (W) \\
\hline & $\mathrm{S}_{1}-$ Membership in UB & $\mathrm{W}_{1}$ - Unwillingness to \\
\hline & $S_{2}$ - Free studies & $\mathrm{W}_{2}$ - Lack of additional \\
\hline & S - Good accommodation & revenue \\
\hline & for students & $\mathrm{W}_{3}$ - Lack of leadership \\
\hline & $\begin{array}{l}\mathrm{S}_{5}-\text { Online access to } \\
\text { scientific data bases and } \\
\text { networks }\end{array}$ & $\begin{array}{l}\mathrm{W}_{4} \text { - Insufficient } \\
\text { cooperation with the } \\
\text { surrounding environment }\end{array}$ \\
\hline Opportunities (O) & SO - Strategy & WO - Strategy \\
\hline $\begin{array}{l}\mathrm{O}_{1}-\text { Cooperation with } \\
\text { alumni }\end{array}$ & \multirow[t]{4}{*}{$\begin{array}{l}\mathbf{S O}_{1}-\text { Strategy for } \\
\text { development of new markets }\end{array}$} & \multirow{3}{*}{$\begin{array}{l}\mathbf{W} \mathbf{O}_{1}-\text { Strategy of the shift } \\
\text { in the management of the } \\
\text { Faculty }\end{array}$} \\
\hline $\mathrm{O}_{2}$ - International exchange & & \\
\hline $\begin{array}{l}\mathrm{O}_{3} \text { - Increased demands for } \\
\text { quality }\end{array}$ & & \\
\hline $\mathrm{O}_{4}$ - Access to EU funds & & \\
\hline
\end{tabular}




\section{Threats (T)}

$\mathrm{T}_{1}$ - Declining number of potential students

$\mathrm{T}_{2}$ - Declining living standard in Serbia

$\mathrm{T}_{3}$ - Lack of students' motivation

$\mathrm{T}_{4}$ - Declining level of input knowledge of new students

$\mathrm{T}_{5}$ - Inconsistency of state policy

\section{ST - Strategy}

$\mathbf{S T}_{1}-$ The strategy of product development (development of new and attractive study programs)

\section{WT - Strategy}

$\mathrm{WT}_{1}-$ Strategy for formation of the strategic partnerships within the BU and $\mathrm{EU}$

Step 2) Based on the rankings of the expert team the importance of each SWOT factor (criteria) in the model is determined, while their internal interdependence was not considered, but only importance in relation to the objective that is set within level 1 (see Figure 1b). The resulting importance of each SWOT factor is shown in Table 3, where it can be seen that the greatest importance, based on scores of the expert team, has the SWOT factor Opportunities ( $42 \%$ importance).

Table 3

Pairwise comparison of SWOT groups without interdependences between them

\begin{tabular}{lllccc}
\hline \multicolumn{1}{c}{ SWOT group } & $\mathrm{S}$ & $\mathrm{W}$ & $\mathrm{O}$ & $\mathrm{T}$ & $\begin{array}{c}\text { Importance of the } \\
\text { SWOT factor }\end{array}$ \\
\hline Strengths (S) & 1 & 2 & $1 / 3$ & $1 / 2$ & 0.168 \\
Weaknesses (W) & & 1 & $1 / 2$ & $1 / 3$ & 0.123 \\
Opportunities (O) & & 1 & 2 & 0.420 \\
Threats (T) & & & 1 & 0.289 \\
\hline Consistency ratio relative to the goal: $\mathrm{CR}=0.06$ \\
\hline
\end{tabular}

From Table 3, it follows that:

$$
\mathrm{w}_{1}=\left[\begin{array}{c}
\mathrm{S} \\
\mathrm{W} \\
\mathrm{O} \\
\mathrm{T}
\end{array}\right]=\left[\begin{array}{l}
0.168 \\
0.123 \\
0.420 \\
0.289
\end{array}\right]
$$

Step 3) In this step, the inner interdependence of the SWOT factors is determined according to the model defined in Figure 2. Tables 4-7, show the ranks of compared pairs of SWOT factors, which are evaluated by the expert team, as well as the resulting weight vectors of internal interdependences of SWOT factors. 
Table 4

Matrix of internal interdependencies of SWOT groups in relation to Strengths

\begin{tabular}{lllll}
\hline Strengths (S) & $\mathrm{W}$ & $\mathrm{O}$ & $\mathrm{T}$ & Relative importance weight \\
Weaknesses (W) & 1 & $1 / 5$ & $1 / 7$ & 0.075 \\
Opportunities (O) & & 1 & $1 / 2$ & 0.330 \\
Threats (T) & & 1 & 0.595 \\
\hline Consistency ratio relative to the goal: $\mathrm{CR}=0.014$
\end{tabular}

Table 5

Matrix of internal interdependencies of SWOT groups in relation to Weaknesses

\begin{tabular}{lllll}
\hline Weaknesses (W) & $\mathrm{S}$ & $\mathrm{O}$ & $\mathrm{T}$ & Relative importance weight \\
Strengths (S) & 1 & 3 & 6 & 0.635 \\
Opportunities (O) & & 1 & 5 & 0.290 \\
Threats (T) & \multicolumn{5}{l}{0.075} \\
\hline Consistency ratio relative to the goal: $\mathrm{CR}=0.09$ \\
\hline
\end{tabular}

Table 6

Matrix of internal interdependencies of SWOT groups in relation to Opportunities

\begin{tabular}{lllll}
\hline Opportunities (O) & $\mathrm{S}$ & $\mathrm{W}$ & $\mathrm{T}$ & Relative importance weight \\
Strengths (S) & 1 & $1 / 3$ & $1 / 4$ & 0.124 \\
Weaknesses (W) & & 1 & $1 / 2$ & 0.517 \\
Threats (T) & \multicolumn{3}{l}{0.359} \\
\hline Consistency ratio relative to the goal: $\mathrm{CR}=0.01$ \\
\hline
\end{tabular}

Table 7

Matrix of internal interdependencies of SWOT groups in relation to Threats

\begin{tabular}{lllll}
\hline Threats (T) & $\mathrm{S}$ & $\mathrm{W}$ & $\mathrm{O}$ & Relative importance weight \\
Strengths (S) & 1 & $1 / 3$ & $1 / 3$ & 0.140 \\
Weaknesses (W) & 1 & $1 / 2$ & 0.528 \\
Opportunities (O) & \multicolumn{5}{l}{0.332} \\
\hline \multicolumn{7}{l}{ Consistency ratio relative to the goal: CR $=0.05$} \\
\hline
\end{tabular}

On the basis of the calculated relative importance weights of the SWOT factors, the inner dependence matrix $\mathrm{W}_{2}$ is created, in the form of:

$$
\mathrm{W}_{2}=\left[\begin{array}{cccc}
1 & 0.635 & 0.124 & 0.140 \\
0.075 & 1 & 0.517 & 0.528 \\
0.330 & 0.290 & 1 & 0.332 \\
0.595 & 0.075 & 0.359 & 1
\end{array}\right]
$$

Step 4) Obtained relative importance weights of the SWOT factors in the inner dependence matrix $\mathrm{W}_{2}$, are then used for the "correction" of the initial weights of 
SWOT factors which are defined by the matrix $\mathrm{w}_{1}$, after which importance weights of the SWOT factors become:

$$
\mathrm{W}_{\text {SWOTfactors }}=\mathrm{W}_{2} \times \mathrm{W}_{1}\left[\begin{array}{cccc}
1 & 0.635 & 0.124 & 0.140 \\
0.075 & 1 & 0.517 & 0.528 \\
0.330 & 0.290 & 1 & 0.332 \\
0.595 & 0.075 & 0.359 & 1
\end{array}\right] \times\left[\begin{array}{l}
0.168 \\
0.123 \\
0.420 \\
0.289
\end{array}\right]=\left[\begin{array}{l}
0.169 \\
0.253 \\
0.304 \\
0.274
\end{array}\right]
$$

Based on the newly gained priorities of interdependencies of SWOT factors, it can be noticed that there has been a significant change in the relative importance of the two SWOT factors, namely: the importance of the Weaknesses factor is now increased by $13 \%$ in the model (from $12.3 \%$ to $25.3 \%$ ), while the impact of the most important SWOT factor Opportunities has now declined by $11.6 \%$ compared to the original $42 \%$ and now amounts to $30.4 \%$.

Step 5) In this step, the local importance of SWOT sub-criteria is determined by the expert team, while the ranks of comparative pairs of the SWOT sub-criteria, defined in Table 2, are given in Tables 8-11.

Table 8

Pairwise comparisons of the SWOT sub-criterion - Strengths

\begin{tabular}{lllllll}
\hline Strengths (S) & $\mathrm{S}_{1}$ & $\mathrm{~S}_{2}$ & $\mathrm{~S}_{3}$ & $\mathrm{~S}_{4}$ & $\mathrm{~S}_{5}$ & Local weights \\
\hline $\mathrm{S}_{1}$ - Membership in UB & 1 & 3 & $1 / 2$ & 3 & 3 & 0.287 \\
$\mathrm{~S}_{2}$ - International reputation & & 1 & $1 / 3$ & 3 & 3 & 0.175 \\
$\mathrm{~S}_{3}$ - Free studies & & & 1 & 2 & 3 & 0.353 \\
$\mathrm{~S}_{4}$ - Good accommodation & & & & 1 & 2 & 0.110 \\
for students & & & & 1 & 0.075 \\
$\mathrm{~S}_{5}$ - Online access to \\
$\begin{array}{l}\text { scientific data bases and } \\
\text { networks }\end{array}$ \\
\hline The consistency ratio in relation to the group Strengths: $\mathrm{CR}=0.08$
\end{tabular}

Table 9

Pairwise comparisons of the SWOT sub-criterion - Weaknesses

\begin{tabular}{llllll}
\hline Weaknesses $(\mathrm{W})$ & $\mathrm{W}_{1}$ & $\mathrm{~W}_{2}$ & $\mathrm{~W}_{3}$ & $\mathrm{~W}_{4}$ & Local weights \\
\hline $\mathrm{W}_{1}$ - Unwillingness to change & 1 & 3 & 2 & 3 & 0.431 \\
$\mathrm{~W}_{2}$ - Lack of additional & & 1 & $1 / 3$ & $1 / 2$ & 0.101 \\
revenue & & & & & \\
$\mathrm{W}_{3}$ - Lack of leadership & & & 1 & 4 & 0.333 \\
$\mathrm{~W}_{4}$ - Insufficient cooperation & & & 1 & 0.135 \\
$\begin{array}{l}\text { with the surrounding } \\
\text { environment }\end{array}$ & & & & \\
\hline
\end{tabular}

The consistency ratio in relation to the group Weaknesses: $\mathrm{CR}=0.07$ 
Table 10

Pairwise comparisons of the SWOT sub-criterion - Opportunities

\begin{tabular}{llllll}
\hline Opportunities $(\mathrm{O})$ & $\mathrm{O}_{1}$ & $\mathrm{O}_{2}$ & $\mathrm{O}_{3}$ & $\mathrm{O}_{4}$ & Local weights \\
\hline $\begin{array}{l}\mathrm{O}_{1} \text { - Cooperation with } \\
\text { alumni }\end{array}$ & 1 & $1 / 3$ & $1 / 4$ & $1 / 2$ & 0.094 \\
$\begin{array}{l}\mathrm{O}_{2} \text { - International } \\
\text { exchange }\end{array}$ & 1 & $1 / 2$ & 3 & 0.316 \\
$\begin{array}{l}\mathrm{O}_{3} \text { - Increased demands } \\
\text { for quality } \\
\mathrm{O}_{4}-\text { Access to EU } \\
\text { funds }\end{array}$ & & 1 & 2 & 0.428 \\
\hline The degree of consistency in relation to the group Opportunities: $\mathrm{CR}=0.04$ \\
\hline
\end{tabular}

Table 11

Pairwise comparisons of the SWOT sub-criterion - Threats

\begin{tabular}{|c|c|c|c|c|c|c|}
\hline Threats $(\mathrm{T})$ & $\mathrm{T}_{1}$ & $\mathrm{~T}_{2}$ & $\mathrm{~T}_{3}$ & $\mathrm{~T}_{4}$ & $\mathrm{~T}_{5}$ & Local weights \\
\hline $\begin{array}{l}\mathrm{T}_{1}-\text { Declining number of } \\
\text { potential students }\end{array}$ & 1 & 2 & 3 & 3 & 4 & 0.377 \\
\hline $\begin{array}{l}\mathrm{T}_{2} \text { - Declining living standard } \\
\text { in Serbia }\end{array}$ & & 1 & 3 & 4 & 3 & 0.291 \\
\hline $\begin{array}{l}\mathrm{T}_{3}-\text { Lack of students' } \\
\text { motivation }\end{array}$ & & & 1 & 4 & 3 & 0.177 \\
\hline $\begin{array}{l}\mathrm{T}_{4} \text { - Declining level of input } \\
\text { knowledge of new students }\end{array}$ & & & & 1 & 2 & 0.087 \\
\hline $\begin{array}{l}\mathrm{T}_{5} \text { - Inconsistency of state } \\
\text { policy }\end{array}$ & & & & & 1 & 0.067 \\
\hline
\end{tabular}

Step 6) Global significance of SWOT sub-criteria is obtained by multiplying factor weights from Step 4 and Step 5 among each other, as presented in Table 12.

Table 12

Importance of criteria and sub-criteria of the SWOT analysis

\begin{tabular}{|c|c|c|c|c|}
\hline $\begin{array}{l}\text { SWOT groups - } \\
\text { criteria }\end{array}$ & $\begin{array}{l}\text { Importa } \\
\text { nce of } \\
\text { the } \\
\text { SWOT } \\
\text { group }\end{array}$ & SWOT sub-criteria & $\begin{array}{c}\text { Local } \\
\text { importance } \\
\text { of SWOT } \\
\text { sub- } \\
\text { criterium }\end{array}$ & $\begin{array}{l}\text { The overall } \\
\text { importance } \\
\text { of SWOT } \\
\text { sub-criteria }\end{array}$ \\
\hline \multirow{6}{*}{ Strengths - S } & \multirow{6}{*}{0.169} & $\mathrm{~S}_{1}$ - Membership in UB & & \\
\hline & & $\mathrm{S}_{2}$ - International reputation & 0.287 & 0.049 \\
\hline & & $\mathrm{S}_{3}$ - Free studies & 0.175 & 0.030 \\
\hline & & \multirow{2}{*}{$\begin{array}{l}\mathrm{S}_{4} \text { - Good accommodation for } \\
\text { students }\end{array}$} & $\underline{\mathbf{0 . 3 5 3}}$ & 0.060 \\
\hline & & & 0.110 & 0.019 \\
\hline & & $\begin{array}{l}\mathrm{S}_{5}-\text { Online access to } \\
\text { scientific data bases and } \\
\text { networks }\end{array}$ & 0.075 & 0.013 \\
\hline
\end{tabular}




\begin{tabular}{|c|c|c|c|c|}
\hline \multirow{4}{*}{ Weaknesses - W } & \multirow{4}{*}{0.253} & $\mathrm{~W}_{1}$ - Unwillingness to change & $\underline{0.431}$ & 0.109 \\
\hline & & $\mathrm{W}_{2}$ - Lack of additional revenue & $\overline{0.101}$ & 0.026 \\
\hline & & $\mathrm{W}_{3}$ - Lack of leadership & 0.333 & 0.084 \\
\hline & & $\begin{array}{l}\mathrm{W}_{4} \text { - Insufficient cooperation } \\
\text { with the surrounding } \\
\text { environment }\end{array}$ & 0.135 & 0.034 \\
\hline \multirow{5}{*}{$\begin{array}{l}\text { Opportunities - } \\
\text { O }\end{array}$} & \multirow{5}{*}{0.304} & $\mathrm{O}_{1}$ - Cooperation with alumni & 0.094 & 0.029 \\
\hline & & $\mathrm{O}_{2}$ - International exchange & 0.316 & 0.096 \\
\hline & & $\mathrm{O}_{3}$ - Increased demands for & $\underline{0.428}$ & 0.130 \\
\hline & & quality & $\overline{0.163}$ & 0.050 \\
\hline & & $\mathrm{O}_{4}-$ Access to EU funds & & \\
\hline \multirow{6}{*}{ Threats - T } & \multirow{6}{*}{0.274} & $\begin{array}{l}T_{1}-\text { Reducing the number of } \\
\text { potential students }\end{array}$ & & \\
\hline & & $\begin{array}{l}\mathrm{T}_{2} \text { - Declining living standard } \\
\text { in Serbia }\end{array}$ & $\frac{\mathbf{0 . 3 7 7}}{0.291}$ & $\begin{array}{l}0.103 \\
0.080\end{array}$ \\
\hline & & $\mathrm{T}_{3}$ - Lack of students' & 0.177 & 0.048 \\
\hline & & motivation & 0.087 & 0.024 \\
\hline & & $\begin{array}{l}\mathrm{T}_{4} \text { - Declining level of input } \\
\text { knowledge of new students }\end{array}$ & \multirow[t]{2}{*}{0.067} & 0.018 \\
\hline & & $\begin{array}{l}\mathrm{T}_{5} \text { - Inconsistency of state } \\
\text { policy }\end{array}$ & & \\
\hline
\end{tabular}

Hence it follows that:

$\mathrm{W}_{3}=\mathrm{W}_{\text {SWOTsub-factros(global) }}=\left[\begin{array}{c}0.049 \\ 0.030 \\ 0.060 \\ 0.019 \\ 0.013 \\ 0.109 \\ 0.026 \\ 0.084 \\ 0.034 \\ 0.029 \\ 0.096 \\ 0.130 \\ 0.050 \\ 0.103 \\ 0.080 \\ 0.048 \\ 0.024 \\ 0.018\end{array}\right]$ 
Step 7) In this step, the importance weight of each alternative strategy $\left(\mathrm{SO}_{1}, \mathrm{WO}_{1}\right.$, $\mathrm{ST}_{1}, \mathrm{WT}_{1}$ ) was determined in relation to the defined SWOT sub-criteria, which results in the matrix $\mathrm{W}_{4}$ as following:

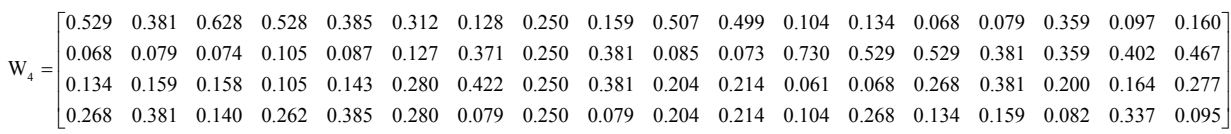

Step 8) Finally, the overall priority of the considered strategies was calculated as follows:

$\mathrm{W}_{\text {alternatives }}=\left[\begin{array}{l}\mathrm{SO} 1 \\ \mathrm{WO1} \\ \mathrm{ST} 1 \\ \mathrm{WT} 1\end{array}\right]=\mathrm{W}_{4} \times \mathrm{W}_{\text {SWOTsub-factros(global) }}=\left[\begin{array}{c}0.271 \\ 0.322 \\ 0.214 \\ 0.192\end{array}\right]$

\section{Discussion of Results}

Application of ANP - SWOT methodology allows prioritization of the identified alternative strategies which are shown in Table 2. The priority, according to the obtained results, is defined in the following descending order: $\mathrm{WO}_{1}-\mathrm{SO}_{1}-\mathrm{ST}_{1}-$ $\mathrm{WT}_{1}$. In the SWOT criteria, according to the proposed ANP model with internal interdependence on level 2 (see Figure 1), the factors which have the most importance are the opportunities $(\mathrm{O})-0.304$, followed by threats $(\mathrm{T})-0.274$ and eventually the weaknesses (W) -0.253 and strengths (S) - 0.169, while the interactions were developed between each SWOT - factor.

The sub-criteria in individual SWOT criteria with the greatest importance according to the ANP are: $\mathrm{S}\left(\mathrm{S}_{3}\right.$ - Free studies: 0.353); $\mathrm{W}\left(\mathrm{W}_{1}\right.$ - Unwillingness to change: 0.431); $\mathrm{O}\left(\mathrm{O}_{3}\right.$ - Increased demands for quality: 0.428); $\mathrm{T}\left(\mathrm{T}_{1}\right.$ - Declining number of potential students: 0.377). These facts have a dominant importance when sub-criteria $\mathrm{S}_{3}$ and $\mathrm{O}_{3}$ are being used to maximize the results of implemented strategies, as well as in defining a series of actions to minimize the influence of $\mathrm{W}_{1}$ and $\mathrm{T}_{1}$.

Mission statement of the TFB is: "The purpose of the TFB's existence is to provide an adequate response to the needs of the younger generation for higher education. Implementation of the teaching process will be realized according to the highest standards, while the best in our field are being chosen as benchmarking partners". The mission statement of the TFB implies continued growth and development in a changing environment, which requires the use of $\mathrm{WO}_{1}$ strategy changing the way the Faculty is managed, from the current approach: nontransparency while maintaining the status quo, into a transparent and aggressive strategy of continuous changes in order to grow and develop using all available 
resources. Due to the limited and declining market for the TFB, after the change in the management style, which is followed by the implementation of the strategy $\mathrm{SO}_{1}$ in parallel with the strategy $\mathrm{WO}_{1}$ or immediately after it, it is necessary to enroll students from other markets by using the adequate aggressive promotion or by opening new study centers outside the seat of the Faculty.

Above mentioned strategies $\mathrm{WO}_{1}$ and $\mathrm{SO}_{1}$ can provide a certain growth and development in the initial phase of further growth and development of the TFB, with a limited reach on the life cycle curve of this organization. After, reaching the limits of growth and development using the outlined $\mathrm{WO}_{1}$ and $\mathrm{SO}_{1}$ strategies, in order to upgrade and improve the life cycle of the TFB, the strategy $\mathrm{ST}_{1}$ should be implemented, which, in accordance with the "mission" statement, implies defining new study programs according to the requirements of prospective students.

From the position achieved after applying strategies $\mathrm{WT}_{1}-\mathrm{SO}_{1}-\mathrm{ST}_{1}$, the TFB will become a desirable partner for the implementation of $\mathrm{WT}_{1}$ - formation of the strategic partnerships with the best institutions within the BU and EU. In this way until 2025 creates a realistic chance of achieving the vision TFB: In this way, realistic chances of achieving the vision of the TFB by the year 2025 will be created: "Achieving distinctive position in the educational space of the South Eastern Europe".

In order to achieve the abovementioned goals, the following strategy implementation sequence should be applied: $\mathrm{WO}_{1}-\mathrm{SO}_{1}-\mathrm{ST}_{1}-\mathrm{WT}_{1}$. This will guide TFB towards the specified strategic goals which are defined in the vision. Also, it will be required to boost the importance of the sub-criteria $\mathrm{S}_{3}$ and $\mathrm{O}_{3}$, with a positive impact on the realization of the strategies labeled with $\mathrm{S}$ and $\mathrm{O}$, and to reduce, through continuous changes, negative impacts of the $W_{1}$ and $T_{1}$ in the strategies labeled with $\mathrm{W}$ and $\mathrm{T}$.

\section{Conclusion}

The traditional SWOT analysis involves an arbitrary ranking criteria and subcriteria independently of each other, ignoring the potential interactions between them. In order to overcome abovementioned shortcomings of the traditional SWOT analysis, an attempt was made in this paper to improve this methodology by using ANP network methodology as an upgrade of the initial SWOT matrix.

The results regarding prioritization of possible development strategies of the TFB until the year 2025, which are obtained by using the ANP-SWOT model, show that by taking into account the interactions between goals (selection of the best strategy), SWOT factors, SWOT sub factors and alternatives (possible strategies) at different hierarchical levels, as well as factors within the clusters at the same level through the ANP network model, prioritization of possible strategic alternatives can be reliably defined.

Values of the final weights in the normalized matrix of possible alternative strategies provide opportunities for prioritization of defined strategies which need 
to be continuously administered during the planning period until 2025, in proportion to the progress, which is achieved with the implementation of the previous strategic alternative.

Obtained results, based on the comprehensive numerical data analysis, will serve as the starting point for benchmarking the position of the TFB in the academic scope of the region, and sustaining it's future upraise and competitiveness.

\section{References}

[1] Porter, M. F., Comparative Strategy: Technique for Analysing Industry and Cometitors, The Free Press, New York, 1980

[2] Gorener, A., Comparing AHP and ANP: An Application of Strategic Decision Making in a Manufacturiung Company, International Journal of Business and Social Science, 3(11) (2012) pp. 194- 2008

[3] Kurttila, M., Pesonen, M., Kangas, J., Kajanus, M., Utilizing the Analytical Hierarchy Process (AHP) in SWOT Analysis - a Hybrid Method and its Application to a Forest Certification Case, Forest Policy and Economics, 1 (2000) pp. 41-52

[4] Hamidi, K., Delbahari, V., Formulating a Strategy for a University using SWOT Technique: A Case Study, Australian Journal of Basic and Applied Sciences, 5(12) (2011) pp. 264-276

[5] Sharifi, A. S., Islamic Azad University Function Analysis with Using the SWOT Model in Order Provide Strategic Guidelines (Case study: Faculty of Humanities), Procedia Social and Behavioral Sciences, 58 (2012) pp. $1535-1543$

[6] Kangas, J., Kurttila M., Kajanus, M., Kangas, A., Evaluating the Management Strategies of a Forestland Estate of S-O-S Approach, Journal of Environmental Management, 69 (2003) pp. 349-358

[7] Dyson, R. G., Strategic Development and SWOT Analysis at the University of Warwick,European Journal of Operational Research, 152 (2004) pp. $631-640$

[8] Yuksel, I., Degdeviren, M., Using the Analytical Network Process (ANP) in a SWOT Analysis- A Case Stady for a Textile Firm, Information Sciences, 177(2007) pp. 3364-3382

[9] Sevkli, M., Oztekin, A., Uysal, O., Torlak, G., Turkuilmaz, A., Delen, D., Development of a Fuzzy ANP-based SWOT Analysis for the Airline Industry in Turkey, Expert Systems with Applications, 39 (2012) pp. 14-24

[10] Kangas, J., Pesonen, M., Kurttila, M., Kajanus, M., A’WOT: Integrating the AHP with SWOT Analysis, Proc. $6^{\text {th }}$ ISAHP 2001, Berne, Switzerland (2001) pp. 189-198 
[11] Kajanus, M., Kamngas, J., Kurttila, M., The Use Value Focused Thinking and the A'WOT Hybrid Method in Tourism Management, Tourism Manegement, 25 (2004) pp. 499-506

[12] Lee, J. W., Kim, S. H., Using Analytical Network Process and Goal Programming for Interdependent Information System for Project Selection, Computers and Operations Research, 27 (2000) pp. 367-382

[13] Gorener, A., Toker, K., Ulucay, K., Application of Combined SWOT and AHP: A Case Study for a Manufacturing Firm, Procedia - Social and Behavioral Sciences, 58 (2012) pp. 1525-1534

[14] Wicraramasinghe, V., Takano, S., Application of Combiuned SWOT and Analytic Hierachy Process (AHP) for Tourism Revival Strategic Marketing Planning: A Case of Sri Lanka Toursm, Journal of the Eastern Asia Society for Transportation Studies, 8 (2009) pp. 1-16

[15] Khamseh, A. A., Fazaueli, M., A Fuzzy Analytical Network Process for SWOT Analysis (Case Study: Drug Distribution Company) Technical Journal of Engineering and Applied Sciences, 3 (18) (2013) pp. 2317-2326

[16] Kheirkhah, A., Babaeianpour, M., Bassiri, P., Development of a Hybrid Method Based on Fuzzy PROMETHEE and ANP in the Framework of SWOT Analysis for Strategic Decisions, International Research Journal of Applied and Basic Sciences, 8 (4) (2014) pp. 504-515

[17] Chang, H. H, Huang, W. C. (2006) Application of a Quantification SWOT Analytical Method. Mathematical and Computer Modelling, 43: 158-169

[18] Saaty, T. L., The Analytical Hierarchy Process, New York: McGrawHill, 1980

[19] Saaty, T. L., Vagras, L. G., Models, Methods, Concepts and Applications of the Analytical Hierarchy Process, Boston, MA: Kluwer Academic Publishers, 2001

[20] Saaty, T. L., Takizawa, M., Dependence and Independence from Linear Hierarchies to Nonlinear Networks, European Journal of Operational Research, 26 (1986) pp. 229-237

[21] Stanujkić, D., Djordjević, B., Djordjević, M., Comparative Analysis of some Prominent MCDM Methods: A Case of Ranking Serbian Banks, Serbian Journal of Management, 8 (2) (2013) pp. 213-241

[22] Savić, M., Djordjević, P., Nikolić, Dj., Mihajlović, I., Živković, Ž., Bayesian Inference for Risk Assessment of the Position of Study Program within the Integrated University: a Case Study of Engineering Management at the Technical Faculty in Bor, Serbian Journal of Management, 9(2) (2014) pp. 231-240 